been made concerning possible sounds associated with the tremor, and three definite observations have been made, all supported by independent observation. (1) A rumble : typical observation by Dr. J. R. Ashworth, of Rochdale, who writes, "I heard a very audible rumble accompanying the swaying movement of the house". (2) A sound like a rushing wind, often said to have been followed by a thud, all taking place at the same time as the swaying. (3) No sound: this was the experience of many who felt the tremor and "knew it could not be bombs because there was no sound". So far, no systematic geographical distribution of the observations of the different types is apparent. In one area observations of all three types were reported. Miss E. F. Bellamy, of the University Observatory, Oxford, felt the earth tremor; but the seismograph at the Observatory was not working at the time. The tremor was not recorded on the disk of the Jagger shock recorder belonging to the British Association, then and now working at Comrie. The tentative reading of the record of the tremor obtained by Mr. E. W. Pollard at Binstead, Isle of Wight, shows that it recorded at $00 \mathrm{~h} .36 \mathrm{~m}$. 27s. G.M.T., and Mr. Pollard remarks that the record he obtained was similar to those resulting from "a tank passing at 100 yds., (2) a submarine depth charge at 5 miles, (3) the Burton explosion". No news has yet been received of any possible recordings by seismographs outside the British Isles.

\section{Report of Seismological Investigations Committee}

THIs Committee of the British Association has just issued its report for 1944. This is its forty-ninth report, and it first records with regret the death of Dr. F. J. W. Whipple, who was chairman of the Committee during 1931-39. It is remarked that Whipple was primarily responsible for the leading place which Kew took in seismology, and it was also due in no small measure to his interest, enthusiasm and skill that the International Seismology Summary (published at Oxford) received such generous support from the International Geodetic and Geophysical Union. During the year there has been no alteration in the location or working of the instruments belonging to the Committee which are out on loan. The Milne-Shaw seismographs are at Oxford, Cape Town, Perth (Western Australia), Edinburgh and Fiji. There is also a clock at Fiji and a Jagger shock recorder at Comrie. Thanks are expressed to the collaborators. Two complete recording units have been dispatched to Bombay, and three spare clocks to Poona. Four Milne-Shaw seismographs are under construction for Bombay. Under war conditions, the preparation and publication of the International Seismological Summary is the sole responsibility of Miss E. F. Bellamy of the University Observatory, Oxford. The first quarter for 1935 has been published and partially distributed, while the computation is complete to the end of July 1935.

\section{Committee on Aids for the Deaf}

Ir has been announced in the House of Commons that the following committee has been appointed to advise and assist the Medical Research Council in promoting research into electro-acoustical problems relating to the design and application of instruments in alleviation of deafness: Dr. W. G. Radley (chairman), Mr. E. J. Barnes, Sir Lawrence Bragg, Mr. N. Fleming, Dr. C. S. Hallpike, Mr. L. C. Pocock and Dr. T. S. Littler (secretary). The Committee has formulated a detailed programme of research, and investigations in which physicists are collaborating with otologists and physiologists are in progress.

\section{Linear Intercepts, Areas and Volumes}

In the two theorems stated by S. I. Tomkeieff in a communication under this title in Nature of January 6 , p. 24, the word "by" was printed instead of "to". The theorems should read as follows :

"1. The average linear intercept of a convex polygon circumscribed to a circle is equal to the average linear intercept of the circle.

" 2 . The average linear intercept of a convex polyhedron circumscribed to a sphere is equal to the average linear intercept of the sphere."

\section{The Night Sky in February}

New moon occurs on Feb. 12d. 17h. 33m. U.T. and full moon on Feb. $27 \mathrm{~d}$. $00 \mathrm{~h} .07 \mathrm{~m}$. The following conjunctions with the moon take place: Feb. 1d. $03 \mathrm{~h}$., Jupiter $4^{\circ}$ N. ; Feb. 10d. $22 \mathrm{~h}$., Mars $0 \cdot 1^{\circ} \mathrm{S}$. ; Feb. 15d. 20h., Venus $8^{\circ}$ N. ; Feb. 2ld. 21h., Saturn $0 \cdot 6^{\circ}$ N. ; Feb. 28d. 06h., Jupiter $3^{\circ} \mathrm{S}$. The following occultations of stars brighter than magnitude 6 take place: Feb. 19d. 18h. 24.4m., $\delta$ Taur. $(D)$; Feb. 19d. 19h. 14.2m., 64 Taur. $(D)$; Feb. 19d. $20 \mathrm{~h}$. $09 \cdot 6 \mathrm{~m} ., 68$ Taur. $(D)$; Feb. 23 d. 2 h. $36 \cdot 8 \mathrm{~m}$., 63 Gemi. (D). The times refer to the latitude of Greenwich and $D$ refers to disappearance. Mercury rises at $7 \mathrm{~h} .04 \mathrm{~m}$. at the beginning of the month and is not well placed for observation; on Feb. 28 the planet is in superior conjunction when it rises at $7 \mathrm{~h} .07 \mathrm{~m}$. Venus is an evening star and sets at $21 \mathrm{~h}$. $10 \mathrm{~m}$. and 21h. $53 \mathrm{~m}$. at the beginning and end of the month respectively. Mars is too close to the sun for favourable observation. Jupiter can be seen throughout the night, rising at $20 \mathrm{~h} .54 \mathrm{~m}$. and $18 \mathrm{~h} .48 \mathrm{~m}$. at the beginning and end of the month respectively. Saturn sets at 5 h. $41 \mathrm{~m}$. on Feb. 1 and at $3 \mathrm{~h} .52 \mathrm{~m}$. on Feb. 28.

\section{Announcements}

Prof. Harold Laski will deliver the first public lecture of the British Association of Chemists at the Caxton Hall, Westminster, on February 14, at 6.30 p.m. His subject will be "The Place of the Scientist in Post-War Administration". Anyone who is interested is invited to attend.

THe Maharaja of Travancore Lord Curzon Prize of the University of Madras has been awarded this year to Mr. S. Rajagopalan of the Indian Institute of Science, Bangalore, for his thesis "Essays in Chemotherapeutical Synthesis", representing the most meritorious original investigation in the physical sciences.

ThE following appointments have recently been made in the Colonial Service: F. H. B. Blackburn, to be agricultural chemist, Barbados; J. V. Harbord, to be agricultural superintendent, British Guiana; T. E. Ryall, to be agricultural officer, Nigeria; J. B. Smart, to be assistant conservator of forests, Kenya; A. Jefferiss, to be chief fruit inspector, Palestine; W. J. Badcock, agricultural officer, Uganda, to be senior agricultural officer, British Solomon Islands Protectorate; W. H. B. Buckhurst, assistant director of lands, mines and surveys, Fiji, to be director of lands mines and surveys, Fiji. 